\title{
The Inhibition of Silver Agglomeration by Gold Activation in Silver Electroless Plating
}

\author{
Seung Hwan Cha, ${ }^{*}$ Hyo-Chol Koo, ${ }^{*}$ and Jae Jeong Kim**,z \\ Research Center for Energy Conversion and Storage School of Chemical Engineering, College of
}

Engineering, Seoul National University, Kwanak-gu, Seoul 151-742, Korea

In Ag electroless plating, Ag agglomeration has been the obstacle to obtain thin Ag films. The crystallographic misfit between the substrate and $\mathrm{Ag}$ can accelerate $\mathrm{Ag}$ agglomeration. In this paper, $\mathrm{Au}$, whose crystallographic characteristics are similar with those of Ag, is used as the activation material. As a result, the Ag layer was deposited in the form of layer-by-layer growth. Therefore, Ag film electrolessly deposited on a substrate activated by Au can be used to manufacture the interconnections in microelectronic devices. In this experiment, the resistivity of the Ag film was measured to $2.5 \mu \Omega \mathrm{cm}$, which was decreased to $1.95 \mu \Omega \mathrm{cm}$ by the annealing process.

(C) 2005 The Electrochemical Society. [DOI: 10.1149/1.1905984] All rights reserved.

Manuscript submitted July 19, 2004; revised manuscript received December 20, 2004. Available electronically May 5, 2005.

With decreasing feature sizes in integrated circuits, the availability of interconnection material showing low resistivity has become essential. ${ }^{1,2}$ In addition, when material with low resistivity is used, the thickness of the interconnections can be reduced, which makes the fabrication of the devices easier. Therefore, due to the lowest bulk resistivity of $1.6 \mu \Omega \mathrm{cm}, \mathrm{Ag}$ has high potential for use in microelectronic devices.

In this paper, electroless plating technology was used to deposit Ag film. Because electroless plating technology has the advantage of enabling uniform film deposition over a large substrate area, it can be used to manufacture the interconnections required for thin-film transistor-liquid crystal display (TFT-LCD). ${ }^{3}$ Recently, Ag electroless plating has been the subject of intensive research, ${ }^{4-11}$ but there is at least one serious problem which remains to be resolved. During $\mathrm{Ag}$ electroless plating on a surface activated by $\mathrm{Pd}$ or $\mathrm{Ag}$, the deposited $\mathrm{Ag}$ is agglomerated together. Therefore, it is difficult to form a thin Ag film by electroless plating. In order to resolve this problem, it was attempted to form Ag-W species. ${ }^{8-10}$ However, because impurity is the main source of high resistivity, it is essential that only Ag is deposited.

In this experiment, a new activation material, $\mathrm{Au}$, was attempted as the activation material for $\mathrm{Ag}$ electroless plating. Traditionally, Pd has been used as the activation material in $\mathrm{Cu}^{3,12,13}$ and $\mathrm{Ag}^{8,10}$ electroless plating. However, as shown in Table $\mathrm{I},{ }^{14}$ there is a lattice mismatch of $5 \%$ between Pd and Ag. This fact can make the adhesion between $\mathrm{Ag}$ and Pd aggravate. Therefore, the substitution of the traditional activation material by $\mathrm{Au}$ is expected to improve the adhesion between $\mathrm{Ag}$ and the substrate.

It is known from Table $\mathrm{I}^{14}$ that $\mathrm{Ag}$ has the same face-centered cubic (fcc) crystal structure as Au. Also, the lattice constants of the two metals have almost identical values. These characteristics improve the bonding between $\mathrm{Ag}$ and $\mathrm{Au}$, which may prevent agglomeration of the Ag. In addition, the resistivity of $\mathrm{Au}, 2.4 \mu \Omega \mathrm{cm}$, is relatively low. Therefore, the presence of $\mathrm{Au}$ in the interconnection has little influence on their resistivity. Table $\mathrm{II}^{15}$ shows the reduction potentials of various metals. Among them, Au has the highest reduction potential among conventional metals. This indicates that $\mathrm{Au}$ can be favorably deposited on a TiN diffusion barrier by means of a displacement reaction. Moreover, because of the strong resistance of Au against oxidation, no metal oxide is generated at the interface between $\mathrm{Au}$ and $\mathrm{Ag}$. These factors can help to avoid the problem of Ag agglomeration.

\section{Experimental}

A blanket wafer whose structure was $\operatorname{TiN}(10 \mathrm{~nm}) / \mathrm{Ti}(15 \mathrm{~nm}) / \mathrm{Si}$ wafer was used as the substrate for Ag electroless plating. TiN layer

\footnotetext{
* Electrochemical Society Student Member.

** Electrochemical Society Active Member.

${ }^{\mathrm{z}}$ E-mail: jjkimm@snu.ac.kr
}

had been deposited to prevent metal from diffusing into the electronic devices. Because TiN is oxidized naturally and Ti oxide is an insulator, it has to be removed by immersion in $1 \% \mathrm{HF}$ solution for 10 min. ${ }^{22}$ Deposition of the activation metal is necessary to perform $\mathrm{Ag}$ electroless plating on the substrate. In this experiment, Pd and $\mathrm{Au}$ were used as the activation metals. Each activation solution was optimized for $\mathrm{Ag}$ electroless plating as follows. The Pd activation solution was composed of $0.1 \mathrm{~g} / \mathrm{L} \mathrm{PdCl} 2,3 \mathrm{~mL} / \mathrm{L} 35 \% \mathrm{HCl}$, and $5 \mathrm{~mL} / \mathrm{L} 50 \% \mathrm{HF}$. The Au activation solution was composed of $0.2 \mathrm{~g} / \mathrm{L} \mathrm{AuCl}_{3}$ and $5 \mathrm{~mL} / \mathrm{L} 50 \% \mathrm{HF}$.

$\mathrm{Ag}$ electroless plating can be carried out on the activated substrate. The Ag electroless plating solution contained $6.5 \mathrm{~g} / \mathrm{L} \mathrm{AgNO}_{3}, 500 \mathrm{~mL} / \mathrm{L} 28 \% \mathrm{NH}_{4} \mathrm{OH}, 28 \mathrm{~g} / \mathrm{L} \mathrm{CoSO} \mathrm{C}_{4} \cdot 7 \mathrm{H}_{2} \mathrm{O}$, $50 \mathrm{~g} / \mathrm{L}\left(\mathrm{NH}_{4}\right)_{2} \mathrm{SO}_{4}$, and $0.025 \mathrm{~g} / \mathrm{L} \mathrm{Mg}(\mathrm{OH})_{2}$. In this electrolyte, Co ion was used as the reducing agent and ammonium salt was added to form the complex of $\mathrm{Ag}$ ion with Co ion. ${ }^{7}$ Finally, the deposited $\mathrm{Ag}$ film was annealed at $350^{\circ} \mathrm{C}$ for $30 \mathrm{~min}$. An annealing process was carried out in vacuum condition with $\mathrm{N}_{2}$ gas purging.

To measure the large-scale surface roughness of deposited Ag, the reflectivity of the surface was measured using a laser beam with a wavelength of $650 \mathrm{~nm}$. X-ray photoelectron spectroscopy (XPS), X-ray diffraction (XRD), atomic force microscopy (AFM), Auger electron spectroscopy (AES), and field emission scanning electron microscopy (FESEM) were used to analyze deposited substrate.

\section{Results and Discussion}

Metal activation was performed after Ti oxide etching using a $1 \% \mathrm{HF}$ solution. In the activation reaction, electrons generated by the oxidation of the substrate cause the activation metal ions to be reduced on the substrate surface. ${ }^{16}$ It was known from XPS analysis that $\mathrm{Pd}$ and $\mathrm{Au}$ species were deposited on the substrate after the activation step (Fig. 1). The reduction potential of $\mathrm{Ti}$ is $-1.63 \mathrm{~V} v s$. normal hydrogen electrode (NHE), which was much lower than that of every metal used as the activation metal in this experiment (Table II). Therefore, all displacement reactions of $\mathrm{Pd}$ and $\mathrm{Au}$ on TiN layer occur spontaneously.

\begin{tabular}{lccc}
\hline Table I. Material property of metals. & \\
Element & $\begin{array}{c}\text { Lattice constant } \\
(\mathrm{nm})\end{array}$ & $\begin{array}{c}\text { Resistivity } \\
(\mu \Omega \mathrm{cm})\end{array}$ \\
\hline $\mathrm{Cu}$ & Crystal structure & 0.362 & 1.7 \\
$\mathrm{Pd}$ & $\mathrm{fcc}$ & 0.389 & 10.7 \\
$\mathrm{Pt}$ & $\mathrm{fcc}$ & 0.392 & 10 \\
$\mathrm{Ru}$ & $\mathrm{fcc}$ & 0.271 & 7.1 \\
$\mathrm{Ag}$ & $\mathrm{hcp}$ & \\
$\mathrm{Au}$ & $\mathrm{fcc}$ & 0.409 & 1.6 \\
& $\mathrm{fcc}$ & 0.408 & 2.4 \\
${ }^{\mathrm{a}} \mathrm{Hexagonal} \mathrm{close} \mathrm{packed.}$ & &
\end{tabular}




\begin{tabular}{ll}
\hline Table II. Reduction potential of metal ion. & \\
Reaction & Reduction potential \\
\hline $\mathrm{Ag}^{+}+\mathrm{e} \leftrightarrows \mathrm{Ag}$ & $E^{0}=0.7991 \mathrm{~V}$ vs. $N H E$ \\
$\mathrm{Au}^{+}+\mathrm{e} \leftrightarrows \mathrm{Au}$ & $E^{0}=1.83 \mathrm{~V}$ vs. $N H E$ \\
$\mathrm{Au}^{3+}+2 \mathrm{e} \leftrightarrows \mathrm{Au}^{+}$ & $E^{0}=1.36 \mathrm{~V}$ vs. $N H E$ \\
$\mathrm{Pd}^{2+}+2 \mathrm{e} \leftrightarrows \mathrm{Pd}$ & $E^{0}=0.915 \mathrm{~V}$ vs. $N H E$ \\
$\mathrm{Ru}^{3+}+3 \mathrm{e} \leftrightarrows \mathrm{Ru}$ & $E^{0}=0.6 \mathrm{~V}$ vs. $N H E$ \\
$\mathrm{Cu}^{+}+\mathrm{e} \leftrightarrows \mathrm{Cu}$ & $E^{0}=0.518 \mathrm{~V}$ vs. $N H E$ \\
$\mathrm{Cu}^{2+}+2 \mathrm{e} \leftrightarrows \mathrm{Cu}$ & $E^{0}=0.339 \mathrm{~V}$ vs. $N H E$ \\
$\mathrm{Cu}^{2+}+\mathrm{e} \leftrightarrows \mathrm{Cu}^{+}$ & $E^{0}=0.161 \mathrm{~V}$ vs. $N H E$
\end{tabular}

Following the activation step, Ag electroless plating was carried out for 10 min. From the FESEM analysis (Fig. 2a), it was found that the Ag layer deposited on Pd was agglomerated. The agglomerated Ag layer lowered the reflectivity of the laser beam by $16 \%$. Even though the Ag electrolessly plated for $10 \mathrm{~min}$ did not form a completely continuous film, it reduced the sheet resistance considerably.

In contrast, it was remarkable that $\mathrm{Ag}$ species deposited on $\mathrm{Au}$ formed perfect film without agglomeration (Fig. 2b). The reflectivity of the deposited Ag film was 7\% better than that of a commercially
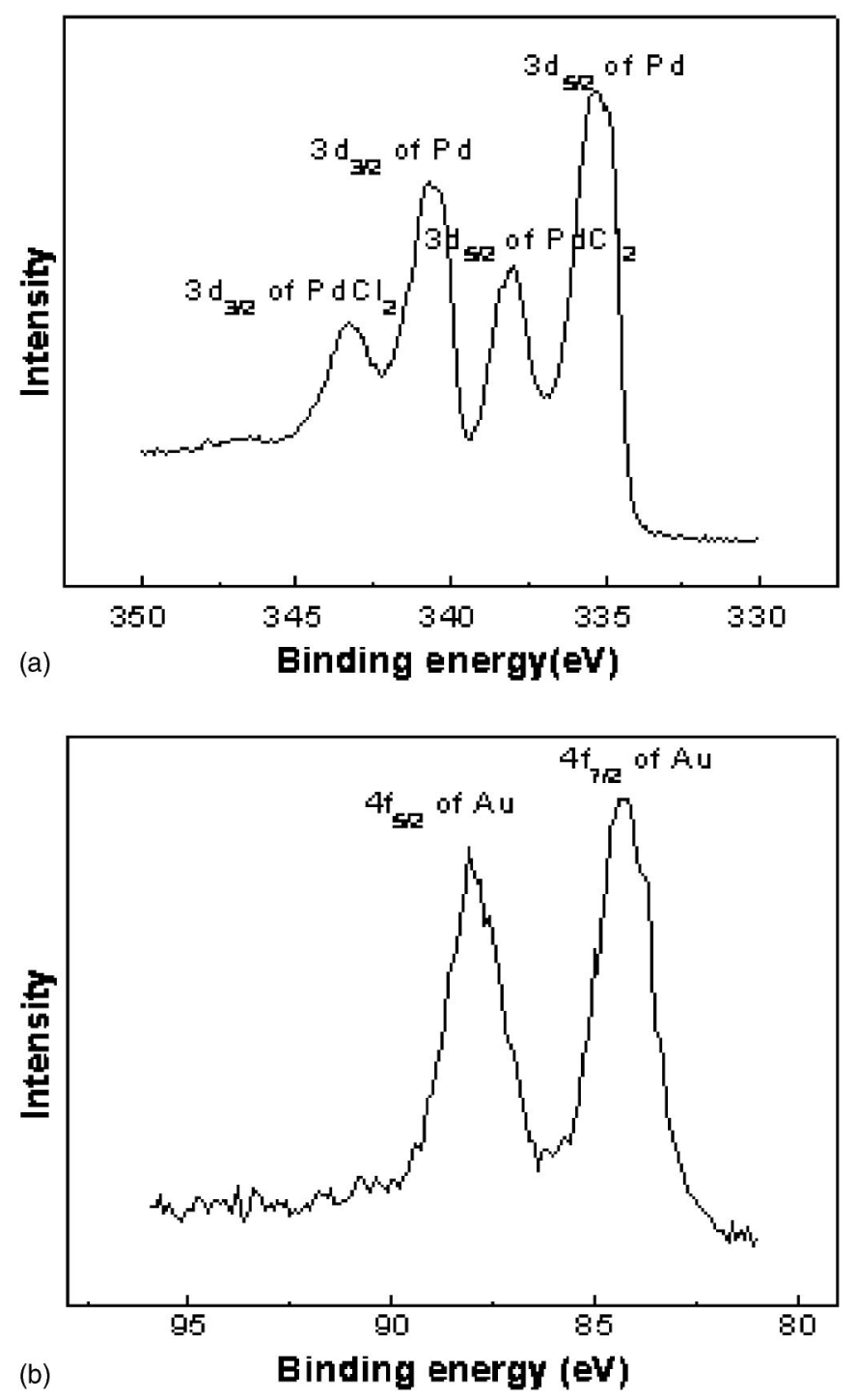

Figure 1. XPS spectra of (a) Pd- and (b) Au-activated surface.
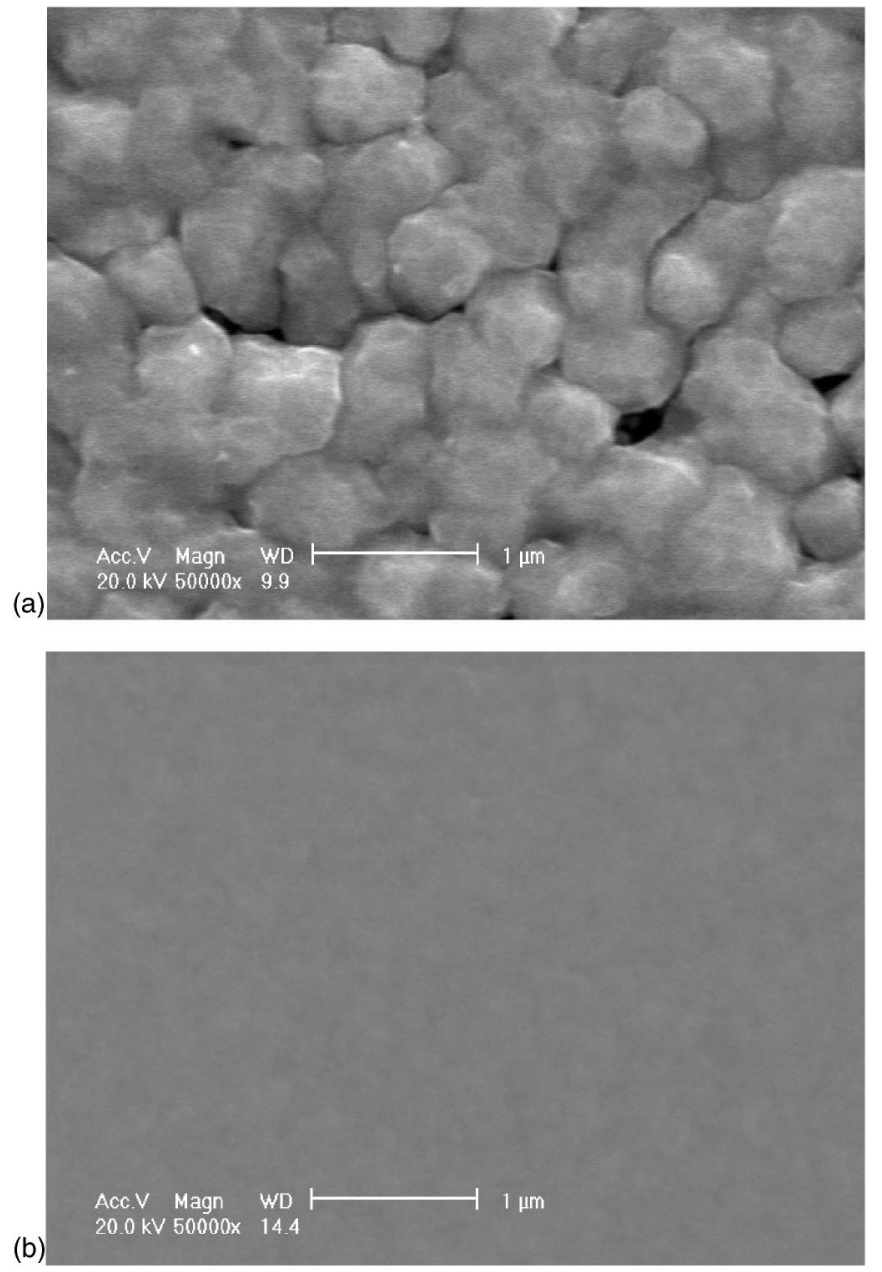

Figure 2. Top FESEM images of Ag species deposited on substrate activated by (a) Pd and (b) Au.

produced mirror. Ag film deposited for $10 \mathrm{~min}$ on the substrate activated by Au showed a thickness of $170 \mathrm{~nm}$ and a surface roughness of $15 \mathrm{~nm}$ (Fig. 3a). The surface roughness of the substrate activated by $\mathrm{Au}$ was $7.9 \mathrm{~nm}$, which indicated that the surface roughness was not substantially increased by Ag electroless plating (Fig. $3 b)$.

To obtain a nonagglomerated Ag film on Pd-activated substrate, $\mathrm{PdCl}_{2}$ concentration in Pd activation solution was changed from 0.1 to $0.4 \mathrm{~g} / \mathrm{L}$. However, $\mathrm{Ag}$ agglomeration always occurred, regardless of $\mathrm{PdCl}_{2}$ concentration. Meanwhile, the surface roughness of $\mathrm{Ag}$ film was increased when $\mathrm{AuCl}_{3}$ concentration was increased to $0.5 \mathrm{~g} / \mathrm{L}$, but $\mathrm{Ag}$ agglomeration was not generated. It is well known in electroless plating that rough surface is obtained when using a roughly activated surface in conjunction with a high concentration of the metal species. ${ }^{12}$ Therefore, the activation material rather than the activation state is the key factor in preventing $\mathrm{Ag}$ agglomeration.

Metal is deposited on foreign substrate via 3 different deposition mechanisms: Volmer-Weber growth mode (3D island formation), Frank-van der Merwe growth mode (layer-by-layer formation), and Stranski-Krastanov growth mode (3D island formation on top of predeposited 2D overlayers). The most important parameters determining the deposition mechanism are the metal-substrate binding energy and the crystallographic misfit. ${ }^{17}$ In order for film formation to proceed via the process of layer-by-layer growth, the binding energy between the substrate and the deposited metal must be higher than that in the deposited metal, and the crystallographic misfit between the substrate and deposited metal must be small. 

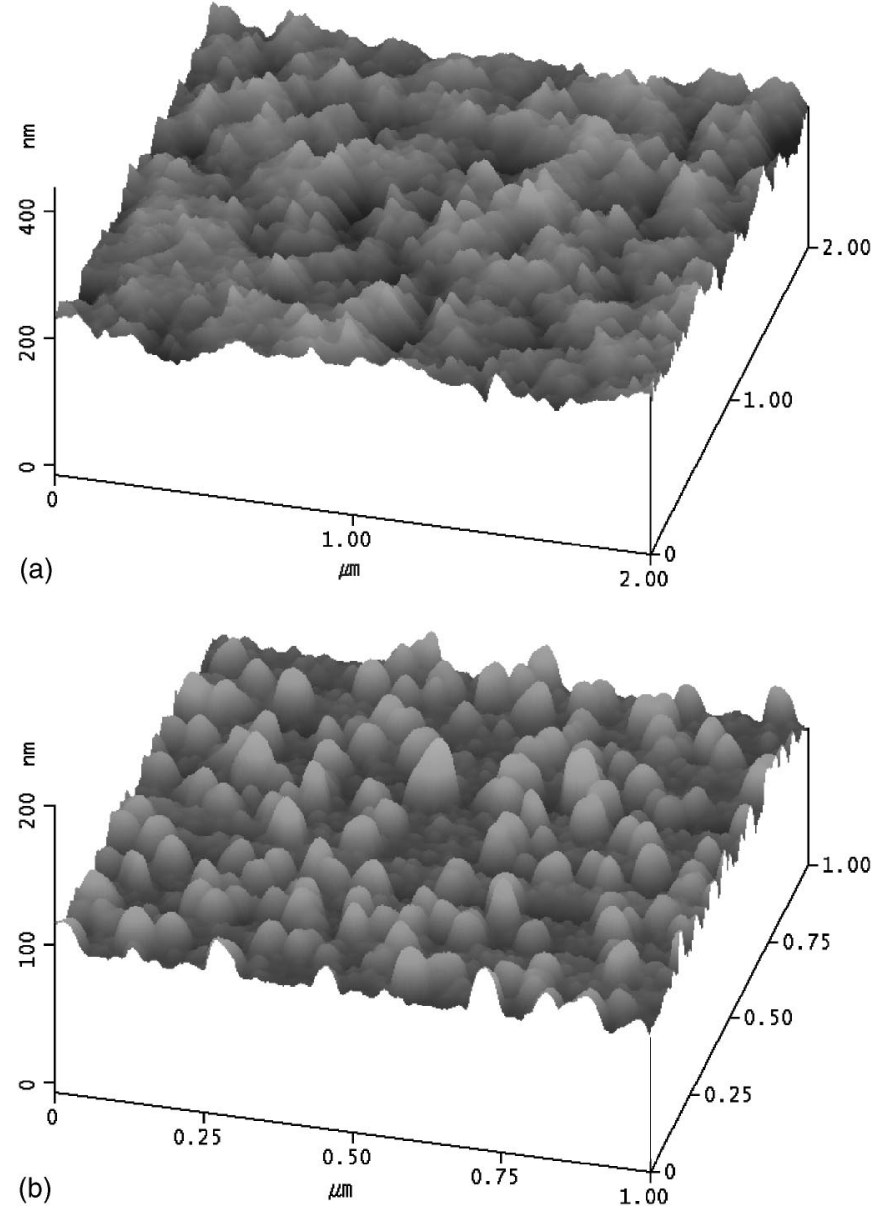

Figure 3. AFM images of (a) Ag-deposited surface on substrate activated by $\mathrm{Au}$ and (b) Au-activated surface.

While Ag-Ag binding energy is $160.3 \mathrm{~kJ} / \mathrm{mol}, \mathrm{Ag}-\mathrm{Au}$ binding energy is $202.9 \mathrm{~kJ} / \mathrm{mol} .{ }^{18}$ As shown in Table I, Ag has the same fcc crystal structure as Au. Also, the lattice constants of two metals have almost identical values. Therefore, Ag film can be deposited in layer-by-layer growth mode without agglomeration, when $\mathrm{Ag}$ is plated on a substrate activated by Au.

In the case of Pd, Pd has the same fcc crystal structure as Ag. However, the lattice constant of $\mathrm{Pd}$ is smaller by $5 \%$ than that of $\mathrm{Ag}$, and Ag-Pd binding energy is $185 \mathrm{~kJ} / \mathrm{mol} .{ }^{19}$ Lattice mismatch and weak binding energy between $\mathrm{Ag}$ and $\mathrm{Pd}$ result in $\mathrm{Ag}$ agglomeration.

The incubation time was measured to determine at which time Ag film formed. The incubation time can be obtained by measuring the sheet resistance as a function of the deposition time. The reciprocal of the sheet resistance had a linear relationship with the deposition time, $2.5 \mathrm{~min}$ after the deposition of Ag (Fig. 4). In the case of Pd activation, however, the incubation time was found to be $4.4 \mathrm{~min}$. In other words, Au activation is more favorable to the formation of $\mathrm{Ag}$ film by electroless plating than Pd activation.

The amount of activated $\mathrm{Au}$ in the $\mathrm{Ag}$ film was low enough for it not to be detected by AES analysis (Fig. 5). Moreover, no impurities were detected in deposited $\mathrm{Ag}$ film. Therefore, the resistivity of $\mathrm{Au}$ in the interface does not pose a serious problem. Nevertheless, the resistivity of the Ag film deposited for $10 \mathrm{~min}$ on a substrate activated by $\mathrm{Au}$ was found to be $2.5 \mu \Omega \mathrm{cm}$. This value is much higher than the bulk resistivity of $\mathrm{Ag}, 1.59 \mu \Omega \mathrm{cm}$. The resistivity of film is affected by grain boundary and defect as well as impurities. ${ }^{20,21}$ The full width at half maximum (fwhm) of the $\mathrm{Ag}(111)$ peak was measured to be 0.0049 in Fig. 6 . From the Scherrer formula, ${ }^{22}$ the

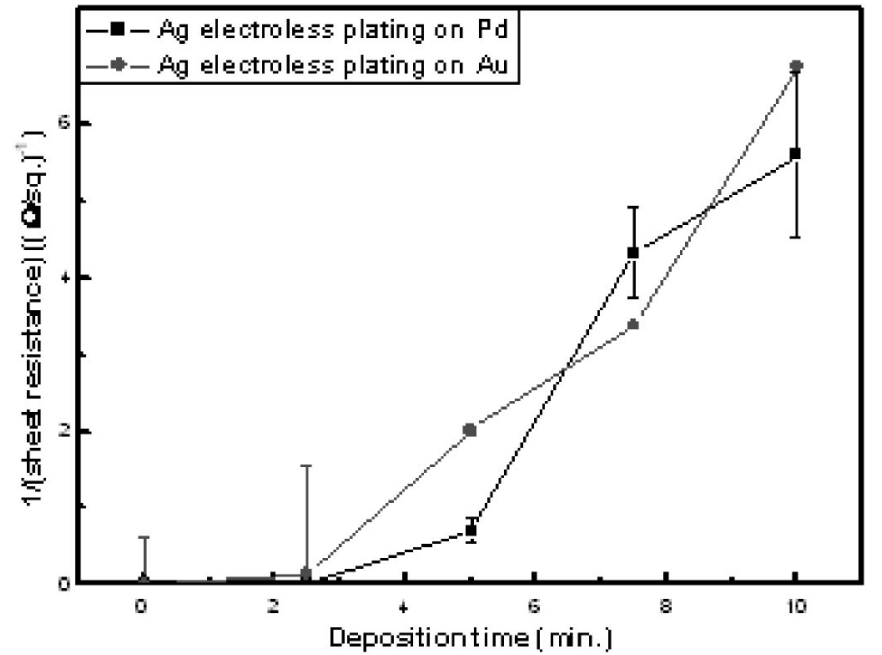

Figure 4. Incubation time measurement from Ag electroless plating on substrate activated by $\mathrm{Au}$ and $\mathrm{Pd}$.

average $\operatorname{Ag}(111)$ grain size was calculated to be about $30 \mathrm{~nm}$. Therefore, grain boundary scattering in Ag film mainly contributed to the increase in the resistivity of film.

This problem could be relieved through the annealing process, which resulted in the resistivity of the Ag film being decreased to $1.95 \mu \Omega \mathrm{cm}$. The annealing process improved the adhesion property as well as the resistivity. In the $3 \mathrm{M}$ tape test, the annealed $\mathrm{Ag}$ film deposited on Au showed good adhesion.

As shown in the results of the XRD analysis in Fig. 6, the crystal structure of the $\mathrm{Ag}$ film deposited on the Au activated surface was superior. Grain size of $30 \mathrm{~nm}$ is comparable to the value of $34 \mathrm{~nm}$ that is found for Ag deposited on a Pd-activated surface. In principle, the average metal grain size increases during annealing in terms of agglomeration. ${ }^{23}$ This phenomenon results from the surface diffusion that occurs at high temperature. ${ }^{24}$ In this paper, however, $\mathrm{Ag}$ agglomeration was generated on the Pd-activated surface by a Volmer-Weber growth mode mechanism. Therefore, the activation metal did not have any effect on the average grain size.

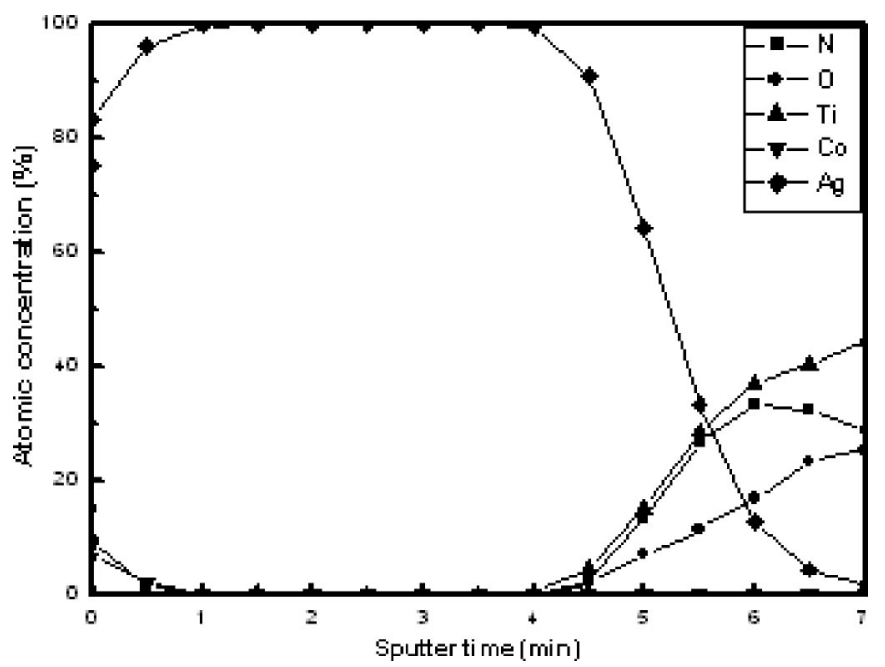

Figure 5. AES spectra of Ag film deposited for $10 \mathrm{~min}$ on substrate activated by $\mathrm{Au}$. 


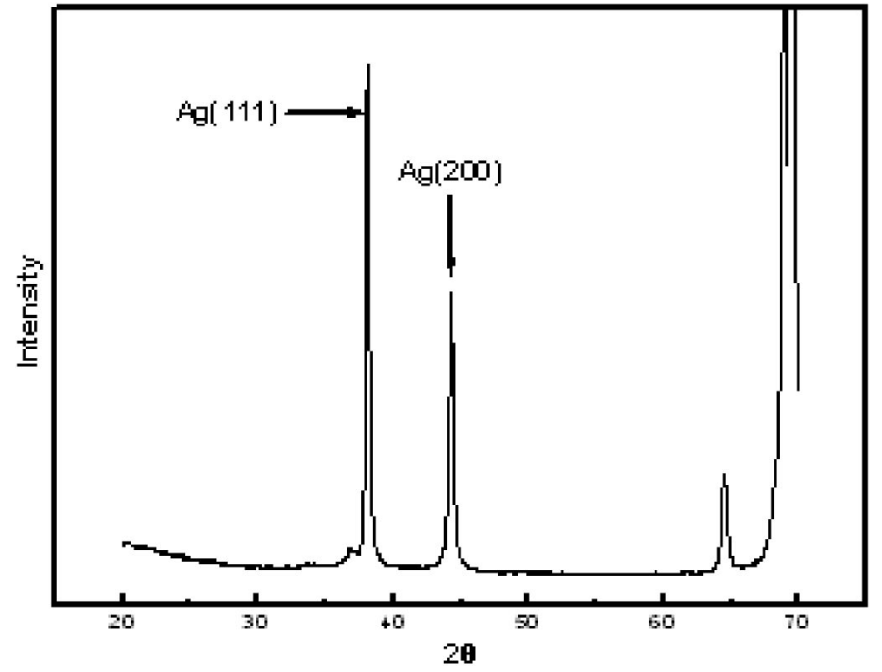

Figure 6. XRD pattern of Ag film deposited for $10 \mathrm{~min}$ on substrate activated by $\mathrm{Au}$.

\section{Conclusion}

Due to the intrinsic crystallographic misfit between Ag and Pd, when $\mathrm{Ag}$ is deposited on $\mathrm{Pd}$ it is agglomerated together. However, $\mathrm{Au}$ prevents the electrolessly deposited Ag from becoming agglomerated, because $\mathrm{Ag}$ - $\mathrm{Au}$ binding energy is higher than $\mathrm{Ag}-\mathrm{Ag}$ binding energy and the crystallographic characteristics of $\mathrm{Ag}$ are similar to those of $\mathrm{Au}$. As a result, a thin $\mathrm{Ag}$ film can be obtained, which can be used for the interconnections in microelectronic devices. The Au activation method reduces the surface roughness of $\mathrm{Ag}$ and the incubation time of $\mathrm{Ag}$ electroless plating. The resistivity of $\mathrm{Ag}$ film was measured to $2.5 \mu \Omega \mathrm{cm}$, which was decreased to $1.95 \mu \Omega \mathrm{cm}$ as a result of the annealing procedure. Therefore, Au activation is essential in order to obtain a nonagglomerated $\mathrm{Ag}$ film by electroless plating.

\section{Acknowledgments}

This work was supported by KOSEF through the Research Center for Energy Conversion and Storage (RCECS), also by the Institute of Chemical Processes (ICP) in Seoul National University and DongbuAnam Semiconductor.

Seoul National University assisted in meeting the publication costs of this article.

\section{References}

1. R. Manepalli, F. Stepniak, S. A. Bidstrup-Allen, and P. A. Kohl, IEEE Trans. Adv. Packag., 22, 4 (1999).

2. M. Hauder, J. Gstöttner, W. Hansch, and D. Schmitt-Landsiedel, Appl. Phys. Lett., 78, 838 (2001)

3. J. J. Kim and S. H. Cha, Jpn. J. Appl. Phys., Part 2, 41, L1269 (2002).

4. A. Vaškelis, A. Jagminienè, and L. Tamašauskaitē-Tamašiūnaitè, J. Electroanal. Chem., 521, 137 (2002).

5. E. Norkus, A. Vaškelis, A. Jagminienè, and L. Tamašauskaitē-Tamašiūnaitè, $J$. Appl. Electrochem., 31, 1061 (2001).

6. A. Vaškelis, A. Jagminiené, R. Juškenas, E. Matulionis, and E. Norkus, Surf. Coat. Technol., 82, 165 (1996).

7. A. Vaškelis and E. Norkus, Electrochim. Acta, 44, 3667 (1999).

8. A. Inberg, L. Zhu, G. Hirschberg, A. Gladkikh, N. Croitoru, Y. Shacham-Diamand, and E. Gileadi, J. Electrochem. Soc., 148, C784 (2001).

9. A. Inberg, Y. Shacham-Diamand, E. Rabinovich, G. Golan, and N. Croitoru, Thin Solid Films, 389, 213 (2001)

10. Y. Shacham-Diamand, A. Inberg, Y. Sverdlov, and N. Croitoru, J. Electrochem. Soc., 147, 3345 (2000).

11. M. V. ten Kortenaar, J. J. M. de Goeij, Z. I. Kolar, G. Frens, P. J. Lusse, M. R. Zuiddam, and E. van der Drift, J. Electrochem. Soc., 148, C28 (2001).

12. J. J. Kim and S. H. Cha, Jpn. J. Appl. Phys., Part 1, 40, 7151 (2001).

13. J. J. Kim, S. H. Cha, and Y.-S. Lee, Jpn. J. Appl. Phys., Part 2, 42, L953 (2003)

14. C. Kittel, Introduction to Solid State Physics, p. 23, John Wiley \& Sons, New York (1996).

15. A. J. Bard and L. R. Faulkner, Electrochemical Methods; Fundamentals and Applications, p. 808, John Wiley \& Sons, New York (2001).

16. J. C. Patterson, C. Ni Dheasuna, J. Barrett, T. R. Spalding, M. O'Reilly, X. Jiang, and G. M. Crean, Appl. Surf. Sci., 91, 124 (1995).

17. E. Budevski, G. Staikov, and W. J. Lorenz, Electrochemical Phase Formation and Growth, p. 4, VCH, New York (1996).

18. CRC Handbook of Chemistry and Physics, D. R. Lide, Editor, pp. 9-51, CRC Press, Boca Raton, FL (2000).

19. A. R. Miedema and K. A. Gingerich, J. Phys. B, 12, 2255 (1979).

20. S. Riedel, J. Röber, and T. Geßner, Microelectron. Eng., 33, 165 (1997).

21. D. Josell, C. Burkhard, Y. Li, Y.-W. Cheng, R. R. Keller, C. A. Witt, D. R. Kelley, J. E. Bonevich, B. C. Baker, and T. P. Moffat, J. Appl. Phys., 96, 759 (2004).

22. N. B. Thomsen, A. Horsewell, K. S. Mogensen, S. S. Eskildsen, C. Mathiasen, and J. Bøttiger, Thin Solid Films, 333, 50 (1998).

23. D. C. Agrawal and R. Raj, Acta Metall., 37, 2035 (1989).

24. H. C. Kim, T. L. Alford, and D. R. Allee, Appl. Phys. Lett., 81, 4287 (2002). 